\title{
DEVELOPMENT OF TEST STAND PROTOTYPE FOR RAIL VEHICLES BRAKE COMPONENTS TESTING
}

The paper deals with the new RAILBCOT test stand building reasons explanation. A project features definition is described. There is possible to perform the railway wheel tread profiles wear research under the rail vehicle in operation conditions simulation. This simulation is possible to execute on the test bench. An important feature of the research is the equivalent conicity change analysis. The paper outlines the stand operation principles a main structure components design and components parameters specification, the tests control, data acquisition and data assessment.

Keywords: Wheel/rail contact, test stand, equivalent conicity, brake blocks testing.

\section{Introduction}

Reduction of noise due to rolling contact of wheel and rail for freight cars is one of the principal tasks to be solved by the European railways. Experts of railways companies, industry and universities were engaged during the last about ten years in searching for technical solutions. An important noise reduction of freight cars can be achieved by replacing the cast iron brake shoes by composite brake shoes. Doing that, two directions have been taken into consideration. This is due to the fact that at that time most composite brake shoes friction coefficients were far away from the friction coefficient of the cast iron brake shoes. Applying such friction materials on existing vehicles would cause the change of braking forces acting on the wheels. These types of brake shoes (K-block) show a friction coefficient which is higher than the coefficient of cast iron. Consequently, the application of the "silent" composite brake blocks of type $\mathrm{K}$ affords the adaptation of the braking system of the vehicle, which is costly. For these reasons, the application of K-brake block was proposed for newly built vehicles. For the existing vehicles, solutions having the same friction coefficient as the cast iron brake shoes were requested (LL-Brake blocks). In this case, we can avoid to the modification of the braking equipment of existing freight cars.

\section{Tests of brake components}

For the development of the braking system on the basis of composite brake blocks a lot of research in different areas was carried out:
- Tests on test rigs to improve the friction characteristics under dry, wet and hot conditions including stop braking and braking in severe downhill conditions.

- Tests to inhibit negative influences on the shunting circuits in railway lines.

- Tests under heavy winter conditions to avoid exceeding braking distances of trains due to the influence of snow.

- Thermo mechanical test to avoid high residual stresses in the wheel rigs and important plastic lateral deformations of the wheels.

- Tests to avoid material inclusions into the brake shoes.

- In line test to prove the braking power.

- Downhill test under severe load conditions.

- Test to prove the whole system behaviour under real service conditions including all the seasons (winter, summer, etc.)

- Fuse tests (behaviour under failures in the braking system, handbrake not released, etc.)

As it can be seen from the above, a lot of tests had to be carried out. They were partly based on a long experience, especially based on the application of cast iron brake shoes. Some of them had to be newly developed due to the different behaviour of composite brake shoes in comparison to cast iron brake blocks (for example, winter tests, tests concerning the shunting behaviour, fuse tests). With growing experience it was possible to develop tests on test rigs instead of expensive tests on lines. During the service tests it was observed that under certain conditions and configurations an unfavourable wear concerning especially the treads of the wheels arose. As a consequence, high equivalent conicities were reached partly after short inservice time. As these parameters concern

\footnotetext{
* Juraj Gerlici, Tomas Lack, Jozef Harusinec

Department of Transport and Handling Machines, Faculty of Mechanical Engineering, University of Zilina, Slovakia

E-mail: juraj.gerlici@fstroj.uniza.sk
} 
dynamic vehicle behaviour it is completely understood only by experts of running dynamics.

\section{Equivalent conicity}

What is equivalent conicity? The wheel and the rail have a particular surface geometry in their contact area. In a first approximation the wheel can be described as a cone rolling on a pointed edge. Conicity describes the angle (tangent) of this cone. Equivalent conicity is a measure comparing real geometries with this theoretical model. This makes it possible to compare different wheel geometries in terms of running behaviour [1,2 and 3].

Importance of equivalent conicity: In order to sustain a good running behaviour of the vehicle on the track, to prevent wheel, rail and track damage and, in the worst case, the risk of a derailment the equivalent conicity must remain within given limits. The geometry of the wheel profile is designed in such a way that during operation, equivalent conicity does not exceed these limits due to wheel wear. The values are defined in EN 14363, stating that equivalent conicity in service may not deviate more than $50 \%$ or a maximum of 0.05 from original values.

Different behaviour of cast-iron brake blocks and composite brake blocks (Fig.1): Cast iron brake blocks adapt their contact geometry to the wheel so that there is no influence on the equivalent conicity of the wheels. This is not the case with composite brake blocks. Here, the brake blocks influence the geometry of the wheel profile and, therefore, also equivalent conicity. Therefore, a new element is introduced into the wheel - rail system. It is important that the new system is at least equal to the old one with respect to the wheel/rail contact conditions (compare Fig. 1).

LL-brake block homologation: In the operational tests of LL-blocks the equivalent conicity was not measured systematically with the exception of Switzerland. Here, it was shown that the equivalent conicity values increased too rapidly. If this proves to be the case in other situations, a monitoring system would be required and wheels would have to be re-profiled more often than with cast-iron brake blocks. This would increase the lifecycle-costs, which runs counter to the idea of having a low cost retrofitting possibility.

What are possible reasons for the increase in equivalent conicity? A UIC study showed that the increase in equivalent conicity is probably due to the geometry of the friction surface of the brake block. There are guidelines on the geometry of brake blocks; however it is unclear how they emerged. It is likely that the contact geometry of the brake block has not been adapted to the geometry of the wheel profile.

Possible approach: The issue of equivalent conicity can be approached in two ways:
Determine if higher deviations from original equivalent conicity are possible: This work would define a new limit value for equivalent conicity. Added to this approach a system for monitoring equivalent conicity during operation must be developed and implemented.

Determine if changes in brake block geometry can reduce high increases in equivalent conicity. The change of geometries during operation must be studied and new brake block geometry must be developed and tested. Ideally, brake block geometry is chosen in such a way that there is no influence on the equivalent conicity of the wheel during operation.

Determine if brake shoes can be developed with properties similar to cast iron brake shoes concerning wheel wear.

Opportunities:

Pursuing the suggested steps gives an opportunity to homologate an economically satisfying LL-brake block because wheel wear questions may be solved.

Insights from this work will also help design an optimal K-block which may reduce observed high wheel wear that is observed in certain cases, thus reducing life cycle costs.

Having optimal brake block wear improves the wheel wear which, in turn, optimises rail wear: Finding an optimal solution reduces costs both in operations and in infrastructure.

Influence on regular homologation: This work can be done in parallel to the regular homologation and can be considered to be an economic optimisation. It is suggested, however, that operational tests include measurements of equivalent conicity.

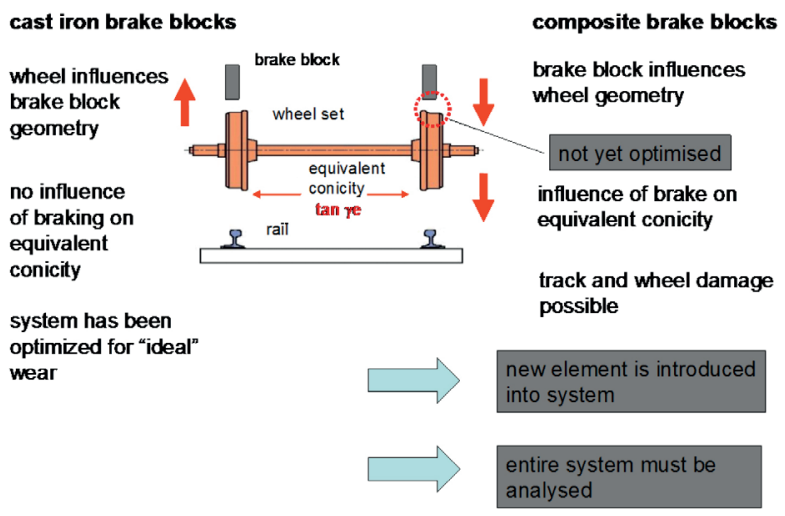

Fig. 1 Wheel wear and equivalent conicity for cast-iron brake blocks and for composite brake blocks

The problems concerning wear on wheels and wear on brake blocks have been found out during service tests. As service tests are very costly and time consuming, there exists a need to perform the tests on a test rig in the future. For these reasons the University of Zilina proposes a research project with the scope of optimization of the interaction between brake shoes and wheels. 


\section{RAILBCOT - Rail vehicles brake parts test stand}

The Railway vehicles brake components test stand RAILBCOT, [4] (see Figs. 2 and 3) is the facility where the core consists of an electromotor position 1 with the power of $440 \mathrm{~kW}$. The motor power is led via a transmission (position 2 - conical gearbox) UNIMEC500 to the discs of rotational rails position 3 . The railway wheelset (position 5) is via a cable stayed transmission (position 6) pressed to these discs with the force of $225.000 \mathrm{~N}$. The wheelset is integrated into the movable frame (position 4) that enables rotating of wheelset about the angle of attack and the lateral movement in the acceptable limits.

During the facility design and conception specification was badly needed to resolve several functional nodes. They are necessary for simulation of the wheelsets drive ability in true railway operation.

Such nodes are:

- change of track gauge possibility,

- change of strike angle possibility,

- lateral forces loading solution,

- axle loading solution.

\section{RAILBCOT - operation principle}

Electromotor (1) will transmit the torque through gearbox (2) which has one input and three output shafts and rotate the rotating rails (3).

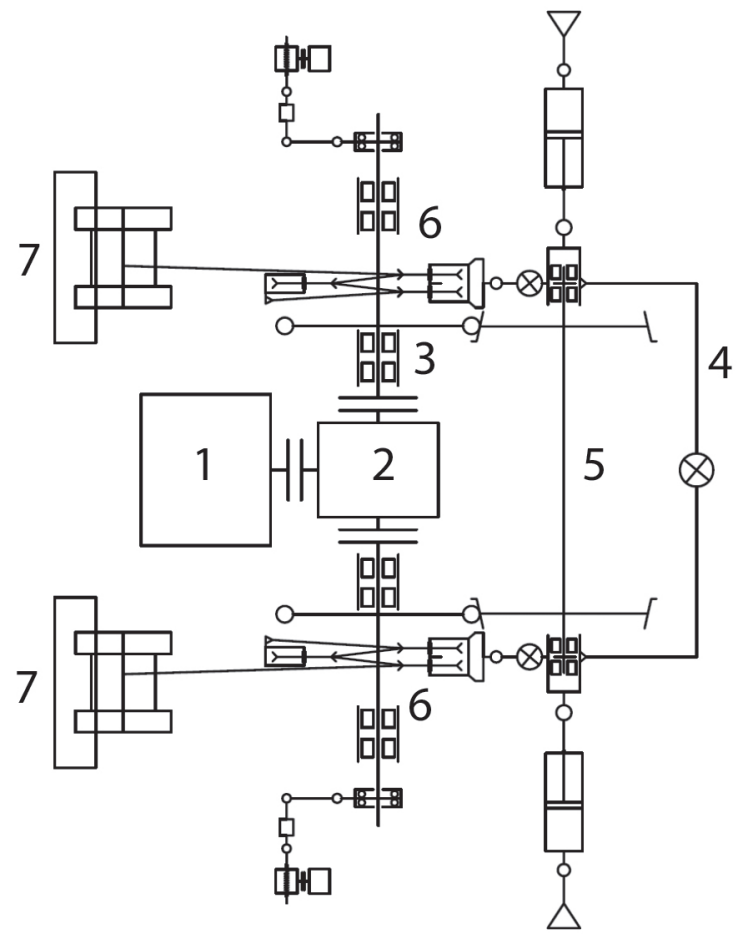

Fig. 2 Schema of the test stand functionality top view
These rotating rails are mounted in bearing housings which are connected with the frame. The supporting frame (4) will hang on two hinges. Rear hinge is of a more simple design and its duty is to hold the support frame in the requested position. Four locomotive brake units are implemented in the support frame. Axle boxes are mounted on the wheelsets (5), they are attached with screw binding to the support frame. A pneumatic cylinder creates the necessary axial force. The front hinge is attached with a tilting lever of the wheelset.

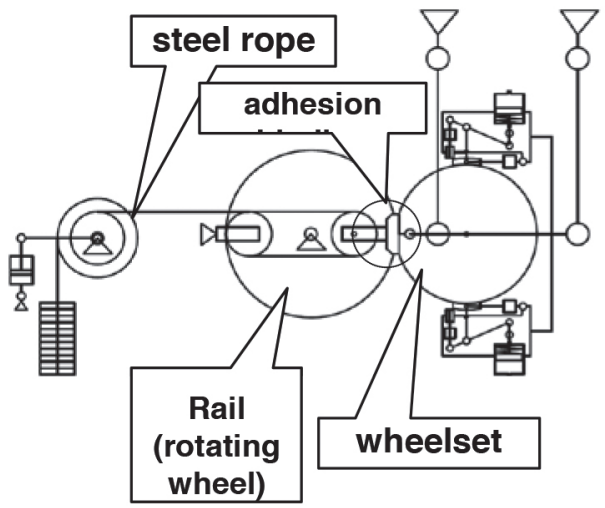

Fig. 3 Schema of the test stand functionality - side view

A force sensor is placed on pull rod which measures the longitudinal forces arising during braking. The adapter is attached to the bearing box in which is a force sensor that is connected to the rope fairlead (6). A vertical wheel force is evoked by weights (7) and each wheel is loaded with one weight. For simulation of the vehicle running arc track the rotating rails are moving in a lateral direction for max. $16 \mathrm{~mm}$. For this change the rotating rail mechanism of transverse displacement is used. This simulates a track gauge change when vehicles are passing the arc. The test bench is placed on two bases.

Scheme of the brake test stand RAILBCOT consists from electromotor, gearbox, rotating rails, brake units, rear hinge, front hinge, support frame, railway wheelset, base, weight units).

Wheel is braked with two locomotive brake units (four units per wheelset). The test stand will be not included into the UIC brake stands branch but ride stands branch. The utilization of the stand, operation and scientific investigation direction is different from Flywheel test stand UIC.

\section{Test stand model}

Three dimensional model of test stand was created in CATIA system. In Fig. 4 is a central executive part of the device. The left side represents the driving part and constitutes the rail the right side (separated by dash dot line) represents a vehicle and constitutes a bogie with railway wheelset. 


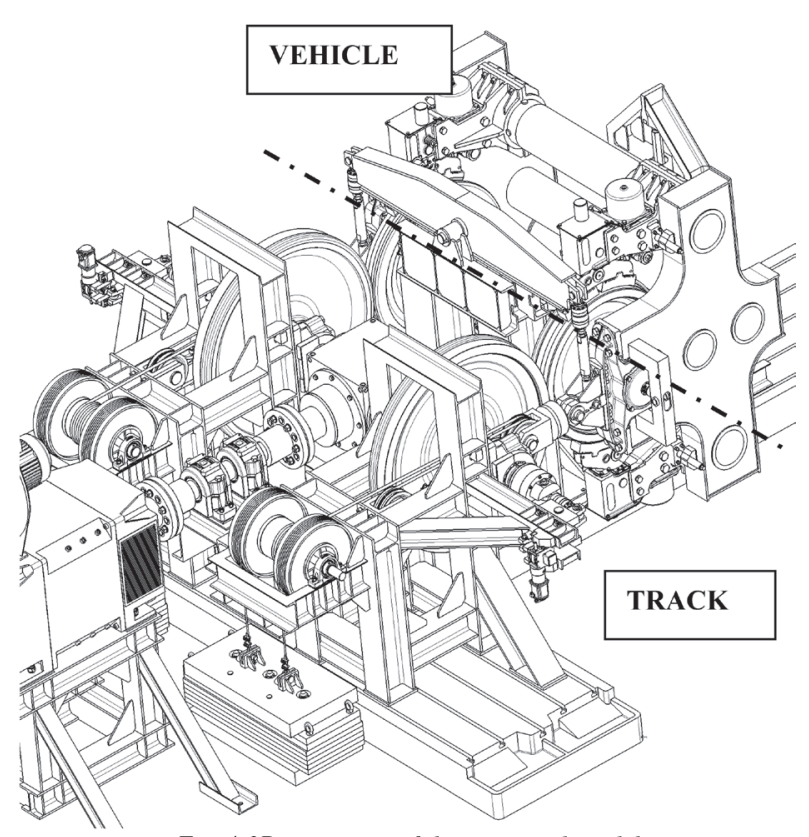

Fig. 4 3D projection of the test stand model

Test stand model-side view is depicted in Fig. 5, test stand modelfront view is in Fig. 6 and test stand model-front view in Fig. 7.

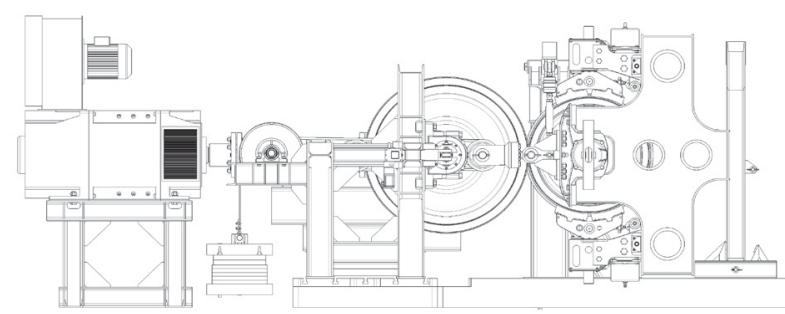

Fig. 5 Test stand model- side view

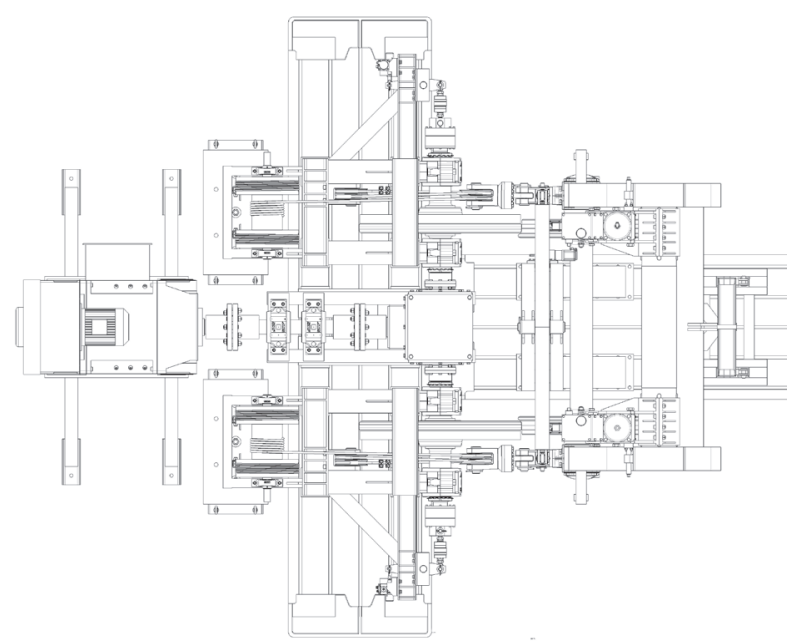

Fig. 6 Test stand model-top view

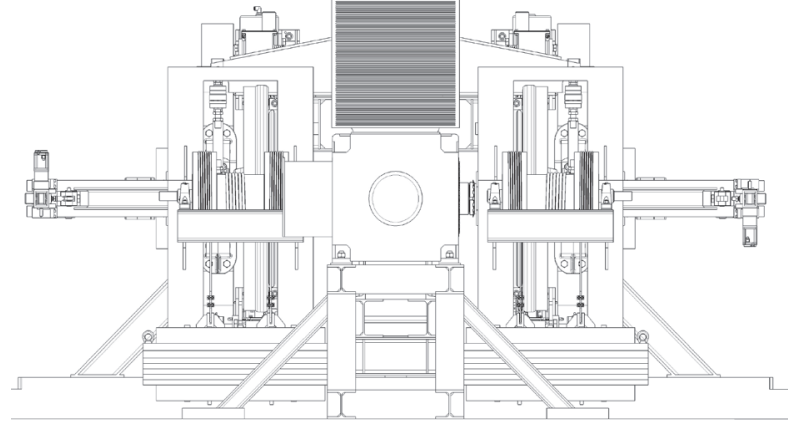

Fig. 7 Test stand model-front view

The test stand is in its basic version equipped with force sensors ( $2 \mathrm{x}$ wheel forces, $2 \mathrm{x}$ forces in the ride direction, $2 \mathrm{x}$ frame lateral forces, $4 \mathrm{x}$ normal brake forces a $4 \mathrm{x}$ tangential brake forces) as well as the wheel revolution sensors and sensors of rail discs. The ground of technical support of data acquisition and data processing are two stations HBM MGC Plus. In the following figures: Fig. 8 is the photo of the PRORAIL test stand - part RAIL and in Fig. 9: PRORAIL test stand facility - part BOGIE.

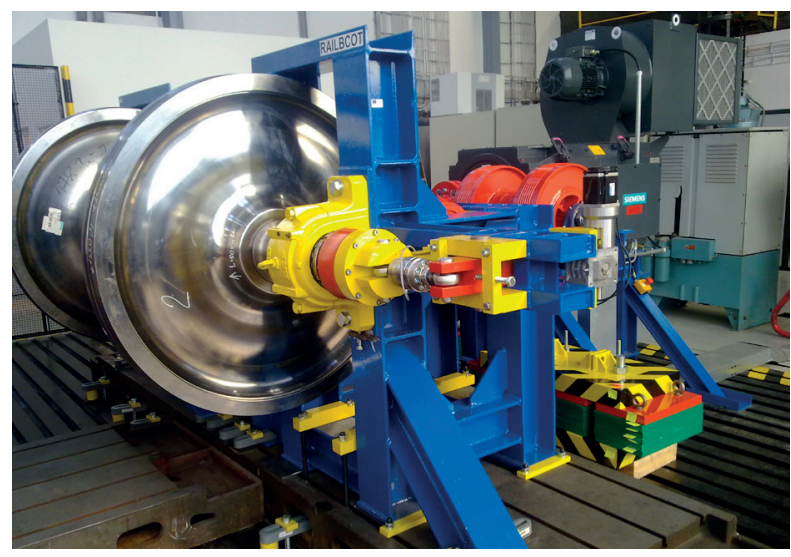

Fig. 8 PRORAIL test stand - part RAIL

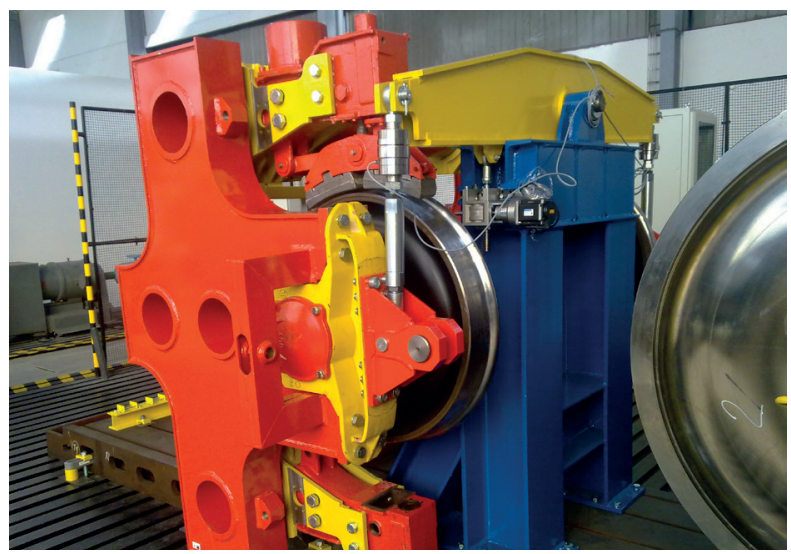

Fig. 9 PRORAIL test stand facility - part BOGIE 


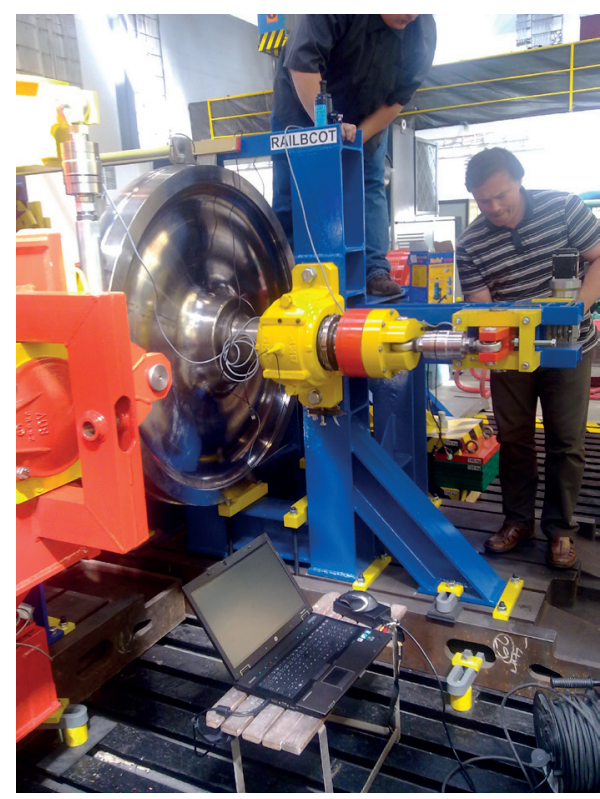

Fig. 10 Parameters tuning

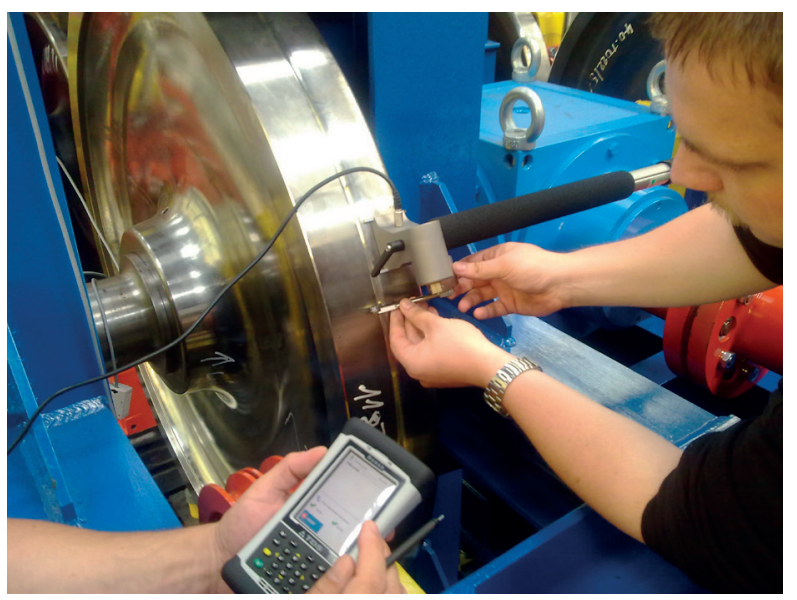

Fig. 11 Rails tread measurement with MiniProf device

Data acquisition (Figs. 10 and 11), data processing and data assessment is performed by means of the "application development environment" written by us and all the test stand control will be guaranteed by this software solution.

\section{Conclusions}

The article deals with the motivation to solve the issue of development, building and utilization of a brand new original test stand. The aim is to create the sophisticated tool for scientific research of railway wheels running tread modification due to wear under simulated operational loads in laboratory conditions. Such tool is the test stand named "RAILBCOT - RAIL Vehicles Brake COmponents Test Stand”, that we are building under ITMS Code 26220220011 project that is mainly based on the support of Research and Development Operational Program financed by European Fund for Regional Development. The principle design, functional demands on device and building of the frames, 3D model building, structural analysis execution, working drawing generation for device part production are results of work of the University working research team. The complete measure chain specification, data acquisition, data assessment and loading running - breaking collection specification are results of the same team.

The project implementation is aimed not only at the solution of one separated, even though very topical and important issue (wheel tread wear).It enables to create presuppositions for performance of new projects aimed at the study of wear wheel/ rail in contact, new wheel or rail profiles development [2, 3, 5 and 6] wheel/rail couple adhesion phenomena, friction conditions of wheel tread / brake block, analysis of wear of rotating members of test stand, temperature and thermal fields spreading, initiation and disposition of stress fields in test specimens (wheelsets, surface stresses in wheels rims, and wheels bodies), wheel unroundness analysis [7], noise transmission and so on. All tests will be supported by the possibility of active input into the realistic, operational loads of railway wheelset.. This test stand offers the possibility of composite materials brake blocks testing [8 and 9], as well as the wheel axles quality evaluating [10, 11 and 12]. The new testing device may be an excellent base tool for international scientific and research cooperation.

\section{Acknowledgements}

This paper was created during the processing of the project "RAILBCOT - RAIL Vehicles Brake COmponents Test Stand", ITMS Code 26220220011 based on the support of Research and Development Operational Program financed by European Fund for Regional Development. The work was also supported by the Scientific Grant Agency of the Ministry of Education of the Slovak Republic and the Slovak Academy of Sciences in project No. 1/0347/12: "Railway wheel tread profile wear research under the rail vehicle in operation conditions simulation on the test bench.”, project No. 1/0383/12: "The rail vehicle running properties research with the help of a computer simulation." and the project No. APVV-0842-11: "Equivalent railway operation load simulator on the roller rig”. 


\section{References}

[1] GERLICI, J., LACK, T.: Railway Wheel and Rail Head Profiles Development Based on the Geometric Characteristics Shapes. Wear, vol. 271, No. 1-2, 2011, 246-258.

[2] GERLICI, J., LACK, T.: Railway Wheel Profile Development Based on the Geometric Characteristics Shapes, Proc. of Contact mechanics and wear of rail/wheel systems, Firenze: AB EDITORE, 2009, 961-967.

[3] GERLICI, J., LACK, T.: Contact Geometry Influence on the Rail / Wheel Surface Stress Distribution, Procedia Engineering, vol. 2, No. 1, 2010, 2249-2257.

[4] GERLICI, J., LACK, T., HARUSINEC, J., MULLER, R., DOLEZEL, P.: RAILBCOT Rail Vehicles Brake Components Test Stand, Proc. of PRORAIL 2011, Scientific and Technical Society at the University of Zilina, 2011, 233-241.

[5] LACK, T., GERLICI, J., DOLEZEL, P.: Analysis of the Wheelset/Rails Interaction on the Roller Rig by Means of Computer Simulation, Proc. of PRORAIL 2011, Scientific and Technical Society at the University of Zilina, 2011, 229-242.

[6] GERLICI, J., LACK, T.: Iterative Method for Railway Wheel Profile Design, Communications - Scientific Letters of the University of Zilina, vol. 11, No. 2, 2009, 49-56.

[7] GERLICI, J., LACK, T.: Rail Roughness and Railway Wheel Unroundness Analysis, Proc. of XVIII konferencja naukowa - pojazdy szynowe : Katowice-Ustron, 2008, 308-318.

[8] KALINCAK, D., REZNICEK, R.: New Brake Materials in Railway Operation. Proc. of BulTrans-2013: anniversary scientific conference on aeronautics, automotive and railway engineering and technologies: Sofia: Izdatelstvo na Techniceskija Universitet, 2013, 91-94.

[9] HRINAK, J., NOVY, F., REZNICEK, R., KALINCAK, D.: Comparison of the Properties of Composite Organic Railway Brake Blocks of Type K with Cast Iron Brake Block P10. Logistyka, Nr. 3, 2012, CD-ROM, 815-823.

[10] NOVOSAD, M., FAJKOS, R., REHA, B., REZNICEK, R.: Fatigue Tests of Railway Axles. Procedia Engineering, No. 1, 2010, 2259-2268.

[11] REZNICEK, R., NOVOSAD, M., REHA, B.: Fatigue Strength of Railway Axles. Materials Engineering, vol. 16, No. 3a, 2009, 46-49.

[12] VASKO, M., LEITNER, B., SAGA, M.: Computational Fatigue Damage Prediction of the Lorry Frames under Random Excitation. Communications - Scientific Letters of the University of Zilina. vol. 12, No. 4, 2010, 62-67. 